\title{
Expression of Matrix Metalloproteinases and Their Tissue Inhibitors in Human Brain Tumors
}

\author{
Klaus Lampert, ${ }^{*}$ Uwe Machein, ${ }^{\dagger}$ \\ Márcia Regina Machein, ${ }^{*}$ Walter Conca, ${ }^{\dagger}$ \\ Hans Hartmut Peter, ${ }^{\dagger}$ and Benedikt Volk* \\ From the Abteilung Neuropathologie," Neurozentrum and \\ Abteilung für Rheumatologie und Klinische Immunologie, ${ }^{\dagger}$ \\ Medizinische Universitätsklinik, Universität Freiburg, Germany
}

In this study, we investigated the expression patterns of 15 matrix metalloproteinases (MMPs) and three tissue inhibitors of metalloproteinase in gliomas, medulloblastomas, and normal brain tissue. By Northern blot analysis we found increased levels of mRNAs encoding for gelatinase $A$, gelatinase $B$, two membrane-type MMPs (mt1- and mt2-MMP), and tissue inhibitors of metalloproteinase- 1 in glioblastomas and medulloblastomas. We observed a significant increase of mt1-MMP, gelatinase $A$, gelatinase $B$, and tissue inhibitors of metalloproteinase-1 in glioblastomas as compared with low-grade astrocytomas, anaplastic astrocytomas, and normal brain. In medulloblastomas, the expression of mt1-MMP, mt2-MMP, and gelatinase A were also increased, but to a lesser extent than that observed in glioblastomas. These data were confirmed at the protein level by immunostaining analysis. Moreover, substrate gel electrophoresis showed that the activated forms of gelatinases $A$ and $B$ were present in glioblastomas and medulloblastomas. These results suggest that increased expression of mt1-MMP/gelatinase A is closely related to the malignant progression observed in gliomas. Furthermore, the present study demonstrates, to our knowledge for the first time, that medulloblastomas express high levels of MMP. (Am J Pathol, :429-437)

Brain tumors are the third most frequent cause of cancerrelated deaths in middle-aged males and the second most common cause of cancer deaths in children. ${ }^{1}$ In adults, malignant gliomas are the most frequent primary brain tumor, whereas in children, medulloblastomas, belonging to the entity of primitive neuroectodermal tumors (PNETs), account for approximately $30 \%$ of central nervous system neoplasms. ${ }^{2}$

For reasons that are poorly understood, most primary brain tumors do not metastasize systemically. ${ }^{3}$ However, they spread locally through extensions of infiltrating tumor cells in normal brain or, more rarely, through cerebral spinal fluid dissemination along the neuroaxis. ${ }^{4}$ Local invasiveness is an important characteristic of gliomas, contributing substantially to the failure of curative treatments. Even low-grade cerebral gliomas are infiltrative, whereas malignant gliomas are widely invasive. The seeding of tumor cells in the neuroaxis is a common feature of PNETs, whereas distant metastases are found in about $15 \%$ of the cases. ${ }^{5}$ These characteristics common to different brain tumors make their complete surgical resection difficult and focal therapy often ineffective. Relapses and recurrences occur not only at the primary site, but also in distant locations. Thus, the understanding of the mechanisms involved in tumor invasiveness within the brain is of high importance to develop new strategies to control local tumor growth.

Clues to the process of tumor invasion have been ascertained through an increased understanding of key roles played by the extracellular matrix, cell adhesion molecules, and proteases. Two families of proteases, the serine proteases of the plasminogen activator/plasmin system and the matrix metalloproteinases (MMPs), have been implicated in tumor invasion. ${ }^{6-10}$ MMPs are a family of structurally related enzymes that degrade macromolecules of the extracellular matrix. The gene family of human MMP comprises at least 15 members. They have been classified into five different classes based on their substrate specificities (collagenases, gelatinases, stromelysins, and others) or on their transmembrane localization (such as the recently described membrane-type MMP class, mt-MMP). ${ }^{11}$ With the exception of stromelysin 3 , all members of the substrate-specific classes of MMP are secreted as inactive proenzymes that require enzymatic cleavage of the propeptide domain for activation. ${ }^{9,12}$ Once secreted and activated, they are inhibited by a family of endogenous inhibitors, the tissue inhibitors of metalloproteinases (TIMPs). ${ }^{13,14}$ The balance between the levels of activated MMP and free inhibitors determines the overall MMP activity. ${ }^{15}$ Maintenance of this critical equilibrium is essential, because a disturbed balance or ratio of MMP and TIMP affects the invasive process. Decreased TIMP gene expression results in in-

Supported by grants from the Zentrum für Klinische Forschung Universitätsklinik Freiburg (to WC and HHP) and SFB 505-A5 (to BV).

Accepted for publication May 20, 1998.

Address reprint requests to Dr. Klaus Lampert, Abteilung Neuropathologie, Neurozentrum, Breisacher Strasse 64, D-79106 Freiburg, Germany. E-mail: lampert@nz11.ukl.uni-freiburg.de.

K. Lampert and U. Machein contributed equally to this study. 
creased tumor invasiveness, whereas overexpression leads to reduced invasive growth in vivo.

A positive correlation between tumor malignancy and MMP levels has been documented in brain tumors. ${ }^{16}$ Previous studies have also shown that glioma cells are able to secrete a number of metalloproteinases and TIMP in vitro. ${ }^{17}$ The production of matrilysin and stromelysin 1 has been reported in glioma cell lines. ${ }^{18}$ Gelatinase $A$ and $B$ production has been shown to be increased in human malignant gliomas. ${ }^{19}$

Although the literature on this subject has grown in recent years, there are only very few systematic studies involving the most representative members of the MMP and TIMP families. The present study was performed to examine the expression pattern of all MMP genes in gliomas and PNETs to determine whether their expression correlates to the invasive potential and to histological grade of these tumors. Similarly, the role played by TIMP in the invasion process and its relationship to secreted MMP was studied at the RNA and protein levels.

\section{Materials and Methods}

\section{Tissue Samples}

Twelve samples of previously untreated cerebral gliomas (low-grade astrocytoma $(n=3)$, anaplastic astrocytoma $(n=2)$, glioblastoma multiforme (GBM; $n=4$,$) and$ samples of medulloblastoma $(n=3)$ were obtained during surgical removal at the Department of Neurosurgery of the Freiburg University Hospital. Histopathological diagnoses were based on the criteria from the latest World Health Organization classification. ${ }^{20}$

Two samples of nonneoplastic brain tissue used as control were obtained during surgical removal of deeply localized meningiomas. Samples were immediately snap frozen in liquid nitrogen and stored at $-80^{\circ} \mathrm{C}$ until analysis.

\section{RNA Extraction and Northern Blot Analysis}

Total RNA was extracted from tissue samples using a two-step protocol. Frozen tissues were pulverized and RNA was prepared in the first step using the guanidinium thiocyanate method according to Chomczynski and Sacchi. ${ }^{21}$ After precipitation with isopropanol, the RNA was redissolved in lysis buffer from the RNeasy mini kit (Qiagen, Hilden, Germany) and prepared according to the manufacturer's instructions. Total RNA (15 $\mu \mathrm{g}$ ) was separated in a $1.4 \%$ denaturing agarose gel containing 2.2 $\mathrm{mol} / \mathrm{L}$ formaldehyde, transferred overnight by capillary blot onto Duralon ultraviolet membrane (Stratagene, La Jolla, CA) and cross-linked with an ultraviolet cross-linker (Stratagene). The membranes were hybridized for 1 hour in Quick Hyb (Stratagene) at $68^{\circ} \mathrm{C}$ with randomly primed ${ }^{32} \mathrm{P}$-labeled cDNA along with the following DNA probes: the 2.1-kb collagenase 1, a 469-bp collagenase 2 fragment, the $1.9-\mathrm{kb}$ collagenase $3,{ }^{22}$ the $2.1-\mathrm{kb}$ gelatinase $\mathrm{A},{ }^{23}$ a 1.7-kb gelatinase $\mathrm{B}$ fragment, ${ }^{24}$ the $1.8-\mathrm{kb}$ stromelysin 1 , the $1.6-\mathrm{kb}$ stromelysin $2,{ }^{22}$ the $1.8-\mathrm{kb}$ stromelysin $3,{ }^{25}$ a $1.1-\mathrm{kb}$ matrilysin fragment, ${ }^{26}$ a 408 -bp human met- alloelastase fragment, a 735-bp RASI fragment, ${ }^{27}$ the 1.2-kb mt1-MMP, ${ }^{28}$ a 495-bp mt2-MMP fragment, a 429-bp mt3-MMP fragment, a 317-bp mt4-MMP fragment, ${ }^{29}$ a 780-bp TIMP 1 fragment (kindly provided by S. Gay), a 357-bp TIMP-2 fragment, a 341-bp TIMP-3 fragment, and the 1.27-kb glyceraldehyde-3-phosphate dehydrogenase (GAPDH). The membranes were washed twice for 15 minutes at $60^{\circ} \mathrm{C}$ in $2 \times$ standard saline citrate, $0.1 \%$ sodium dodecyl sulfate (SDS), and finally in $0.1 \times$ standard saline citrate and $0.1 \%$ SDS for 30 minutes and exposed to Biomax MR film (Kodak) with intensifying screen for 18 to 48 hours at $-80^{\circ} \mathrm{C}$. The mRNA levels were quantified by densitometric analysis using an Image Master System DTS (Pharmacia, Uppsala, Sweden). GAPDH was used as loading control.

\section{Polymerase Chain Reaction Analysis}

Total cellular RNA was extracted as described above. A reverse transcription system (Promega, Madison, WI) was used to generate the first cDNA strand according to the instructions of the manufacturer. Subsequently, a polymerase chain reaction (PCR) was performed using 2 $\mu l$ of the reverse transcription reaction and Taq polymerase (high fidelity; Boehringer Mannheim, Mannheim, Germany) with the following thermocycle parameters: 4 minutes at $94^{\circ} \mathrm{C}$; 31 cycles of 45 seconds at $94^{\circ} \mathrm{C}, 1$ minute at $55^{\circ} \mathrm{C}$, and 1 minute at $72^{\circ} \mathrm{C}$; and 7 minutes at $72^{\circ} \mathrm{C}$. The following oligonucleotide primers were used for PCR: collagenase 1: 5-ATTCTACTGATATCGGGGCTTTGA-3 and 5-ATGTCCTTGGGGTATCCGTGTAG-3 (+683 to + 1092); collagenase 2: 5-ACGGGAAGCCAAATGAGGA-3 and 5-GAGTGAGCGAGCCCCAAAGAAT-3 (+222 to +680); collagenase 3: 5-CCTGGCTGCCTTCCTCTTCTTGA-3 and 5-AACCCCGCATCTTGGCTTTTTC-3 (+15 to +294); stromelysin 1: 5-ATGCCCACTTTGATGATGATGAAC-3; 5-CCACGCCTGAAGGAAGAGATG-3 (+581 to + 1022); stromelysin 2: 5-ATGCGCAAGCCAAGGTGTG-3 and 5-GGAGGGGGAGGTCCGTAGAGA $3 \quad(+257$ to +871); stromelysin 3: 5-GCCGCCGGACGTCCACCACCTC-3 and 5-CAGCGCCCGCCAGAAAGCACGAAC-3 (+103 to +315); matrilysin: 5-TGTTAAACTCCCGCGTCATAGAAA-3 and 5-CTCCTCGCGCAAAGCCAATCAT-3 (+218 to +486); human metalloelastase: 5-GACCGGGCAACTGGACACATCTA-3 and 5-CACGGGCAAAAACCACCAAAAT-3 (+225 to +496); RASI: 5-GCTGGGCCGCTGGAGAAAGAA-3 and 5-CGAGGCGAGTAGACAGCAGCATCC-3 (+300 to +1035); and TIMP-3: 5-TTGGCTCGGGCTCATCGTGCTC-3 and 5-GCCCCGTGTACATCTTGCCATCAT-3, (+9 to +349).

GAPDH primers were used for loading control. For negative control, reverse transcription-PCR was carried out in the absence of RNA. The amplification products were separated in $1.5 \%$ agarose gels.

\section{Substrate Gel Electrophoresis}

Human brain tumor tissues were thawed, weighed, homogenized in Tris buffer $(50 \mathrm{mmol} / \mathrm{L}$ Tris- $\mathrm{HCl}$ and 75 $\mathrm{mmol} / \mathrm{L} \mathrm{NaCl}, \mathrm{pH}$ 7.5) and centrifuged for 20 minutes at 
Table 1. Synopsis of Results*

\begin{tabular}{|c|c|c|c|c|c|c|c|c|c|c|c|c|c|c|}
\hline \multirow{3}{*}{$\begin{array}{c}\text { Sample } \\
\text { no. }\end{array}$} & \multirow{3}{*}{$\begin{array}{c}\text { Patient } \\
\text { age } \\
\text { (years), } \\
\text { sex }\end{array}$} & \multirow{3}{*}{$\begin{array}{l}\text { Tissue } \\
\text { histology, } \\
\text { WHO grade }\end{array}$} & \multicolumn{6}{|c|}{$\begin{array}{c}\text { Expression (densitometric analysis of Northern } \\
\text { Blot: arbitrary units) }\end{array}$} & \multicolumn{2}{|c|}{$\begin{array}{l}\text { Expression } \\
\text { (PCR) }\end{array}$} & \multicolumn{4}{|c|}{ Activation (zymography) } \\
\hline & & & \multirow[b]{2}{*}{$m t-1$} & \multirow[b]{2}{*}{ mt-2 } & \multirow[b]{2}{*}{ Gel. A } & \multirow[b]{2}{*}{ Gel. B } & \multirow[b]{2}{*}{ TIMP-1 } & \multirow[b]{2}{*}{ TIMP-2 } & \multirow[b]{2}{*}{ Mat. } & \multirow[b]{2}{*}{ TIMP-3 } & \multicolumn{2}{|c|}{ Gel. A } & \multicolumn{2}{|c|}{ Gel. B } \\
\hline & & & & & & & & & & & lat. & act. & lat. & act. \\
\hline 1 & $88, M$ & NB & & 0.61 & & & & 4.47 & - & + & + & - & - & - \\
\hline 2 & $67, \mathrm{~F}$ & NB & & 0.60 & & & & 3.19 & - & + & + & - & + & - \\
\hline 4 & $52, M$ & As, II & 0.51 & 1.04 & 0.18 & & & 3.07 & - & + & + & - & + & - \\
\hline 6 & $30, F$ & As, II & 0.12 & & 0.29 & & 0.93 & 0.32 & - & ++ & NT & NT & NT & NT \\
\hline 7 & $41, M$ & As, II & 0.89 & 0.52 & & & & 7.92 & - & + & + & - & - & - \\
\hline 8 & 57, M & $A A, \| I$ & 0.71 & 0.77 & 0.28 & 0.41 & & 4.40 & - & + & + & - & ++ & - \\
\hline 9 & $28, F$ & $A A, I I I$ & & 1.06 & & & & 20.20 & - & ++ & + & - & ++ & - \\
\hline 10 & $32, F$ & GBM, IV & 5.80 & 0.17 & 0.63 & 2.72 & 4.62 & 1.43 & NT & NT & +++ & +++ & +++ & +++ \\
\hline 11 & $58, F$ & GBM, IV & 1.96 & 0.38 & 1.16 & 0.78 & 4.96 & 2.65 & - & + & ++ & + & ++ & ++ \\
\hline 12 & $66, \mathrm{~F}$ & GBM, IV & 2.82 & 0.77 & 3.00 & & 7.63 & 6.45 & + & + & ++ & + & ++ & ++ \\
\hline 13 & $57, \mathrm{~F}$ & GBM, IV & 14.20 & 0.59 & 4.16 & 1.44 & 19.79 & 8.06 & + & + & ++ & + & +++ & +++ \\
\hline 14 & $7, \mathrm{M}$ & PNET, IV & 1.68 & 2.90 & 0.35 & 0.45 & 0.22 & 3.77 & - & ++ & NT & NT & NT & NT \\
\hline 15 & $11, \mathrm{M}$ & PNET, IV & 2.26 & 2.42 & 0.46 & & 0.10 & 4.44 & - & - & + & - & ++ & - \\
\hline 16 & $31, \mathrm{M}$ & PNET-D, IV & 2.44 & & 7.70 & & 0.67 & 2.77 & - & - & ++ & + & ++ & - \\
\hline
\end{tabular}

*Abbreviations: WHO, World Health Organization; NB, normal brain; As, low-grade astrocytoma; AA, anaplastic astrocytoma; GBM, glioblastoma multiforme; PNET, medulloblastoma; PNET-D, desmoplastic medulloblastoma; mt-1, mt1-MMP; mt-2, mt2-MMP; Mat., Matrilysin; Gel., gelatinase; lat., latent form; act., active form; NT, not tested; -, negative expression; +, faint expression; ++ , positive expression; +++, strong expression.

$5000 \times g$. The pellets were discarded, the supernatants were aliquoted, and the protein content was determined using the BCA Protein Assay Reagent (Pierce, Rockford, IL). Samples were mixed with SDS sample buffer in the absence of a reducing agent and incubate for 20 minutes to denature MMP and dissociate MMP-TIMP complexes. Electrophoresis proceeded on $10 \%$ polyacrylamide gels containing $0.1 \%$ SDS and gelatin at a final concentration of $0.12 \%$. After electrophoresis, the gels were washed in $2.5 \%$ Triton X-100 for 1 hour to remove the SDS. During this process, proenzymes are activated autocatalytically. Gels were then incubated for 24 hours at $37^{\circ} \mathrm{C}$ in reaction buffer (50 mmol/L Tris- $\mathrm{HCl}, \mathrm{pH} 7.5,0.15 \mathrm{~mol} / \mathrm{L} \mathrm{NaCl}, 10$ $\mathrm{mmol} / \mathrm{L} \mathrm{CaCl}$, and $0.02 \% \mathrm{NaN}_{3}$ ) and stained with $0.1 \%$ Coomassie Brilliant Blue R 250. After adequate destaining, gelatinolytic activity is detectable as a clear band against blue background.

\section{Immunohistochemistry}

Staining was carried out using immunoperoxidase staining kits for mouse and for rabbit immunoglobulin (Vector Laboratories, Burlingame, CA). The following primary antibodies and corresponding concentrations were used: anti-mt-MMP (114-1F2), $5 \mu \mathrm{g} / \mathrm{ml}$; anti-gelatinase A (425D11), $5 \mu \mathrm{g} / \mathrm{ml}$ (both mouse monoclonal, Calbiochem, Bad Soden, Germany); anti-MMP-9, $10 \mu \mathrm{g} / \mathrm{ml}$ (rabbit polyclonal, Quartett, Berlin, Germany); and anti-TIMP-2, $10 \mu \mathrm{g} / \mathrm{ml}$ (rabbit polyclonal, Biogenesis, Poole, UK).

Surgical specimens were fixed with $4 \%$ paraformaldehyde, embedded in paraffin, and sectioned. After incubation with citrate buffer, endogenous peroxidase activity was blocked with $0.3 \% \mathrm{H}_{2} \mathrm{O}_{2}$ for 30 minutes. After several washes with phosphate-buffered saline, sections were incubated with $2 \%$ normal serum for blocking of nonspecific binding, followed by incubation with the primary antibody in a humid chamber at $4^{\circ} \mathrm{C}$ overnight. After washing in phosphate-buffered saline, the sections were incubated with biotinylated anti-immunoglobulin of the appropriate species specificity followed by avidin-biotinhorseradish peroxidase complex; between each incubation step the slides were washed three times in phosphate-buffered saline. Immunoperoxidase reaction was visualized with 3,3'-diaminobenzidine-HCl (3,3'-diaminobenzidine buffer tablets; Merck, Darmstadt, Germany) and $0.006 \% \mathrm{H}_{2} \mathrm{O}_{2}$. The slides were briefly counterstained with hematoxylin and mounted and examined under a Leitz Dialux 20 EB microscope. Normal serum 2\% was used as control.

For immunofluorescence, an anti-mt-MMP antibody was used at a dilution of $10 \mu \mathrm{g} / \mathrm{ml}$ and counterstained for 3 hours at room temperature with a goat anti-mouseimmunoglobulin G conjugated with Сy3 $(2 \mu \mathrm{g} / \mathrm{ml}$ ) (Rockland Lab, Gilbertsville, PA). Mounted slides were evaluated under a Leica TCS NT microscope.

\section{Results}

\section{Expression of MMP and TIMP Genes in Human Brain Tumors}

To test the expression of MMP and TIMP mRNAs in gliomas, medulloblastomas, and normal brain, we performed Northern blot analysis (Table 1). We found elevated levels of expression of 7 out of 15 MMPs tested and of 2 out of 3 TIMP. The transcripts shown in Figure $1 \mathrm{~A}$ correspond at $2.9 \mathrm{~kb}$ to gelatinase $\mathrm{A}$, at $2.8 \mathrm{~kb}$ to gelatinase $B$, at $0.9 \mathrm{~kb}$ to TIMP-1, at $4.5 \mathrm{~kb}$ to mt1-MMP, at 4.2 $\mathrm{kb}$ to mt2-MMP, at $5.2 \mathrm{~kb}$ to mt3-MMP, and at $1.4 \mathrm{~kb}$ to GAPDH. TIMP-2 transcripts were detected in brain tissues and tumors as a major $3.5-\mathrm{kb}$ band with additional minor bands at 2.3, 1.5, and $1.0 \mathrm{~kb}$ (Figure 1A).

In normal brain, we found high levels of TIMP-2, whereas TIMP-1 and all tested MMPs were expressed at low levels only. Compared with normal brain, mRNAs for 
A

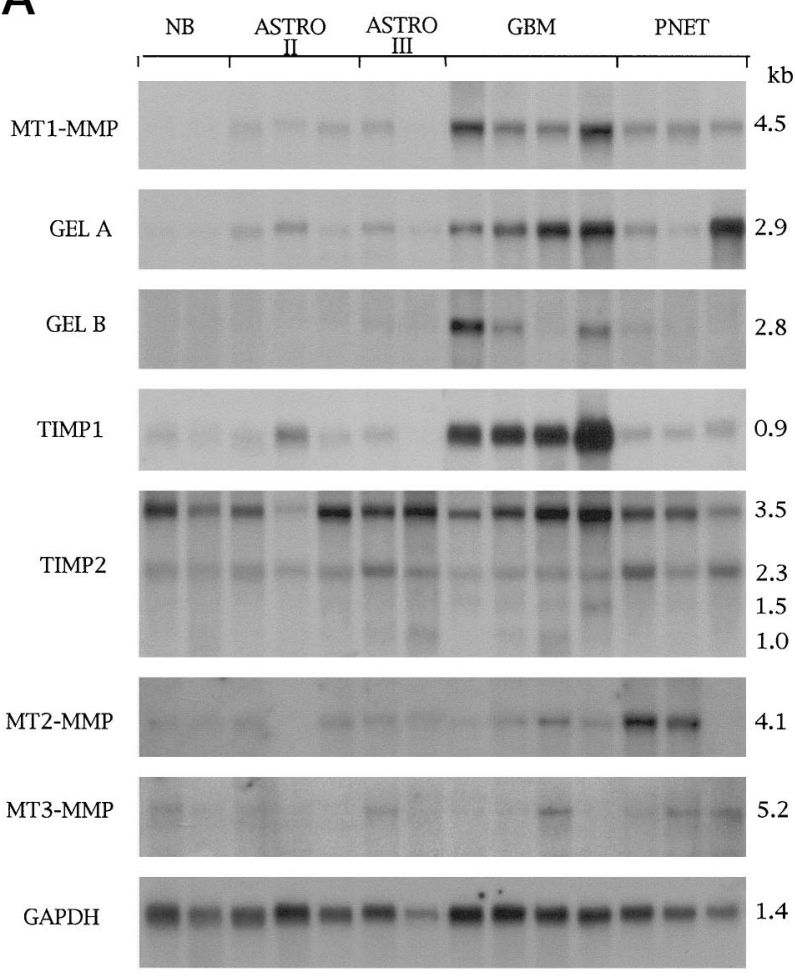

B
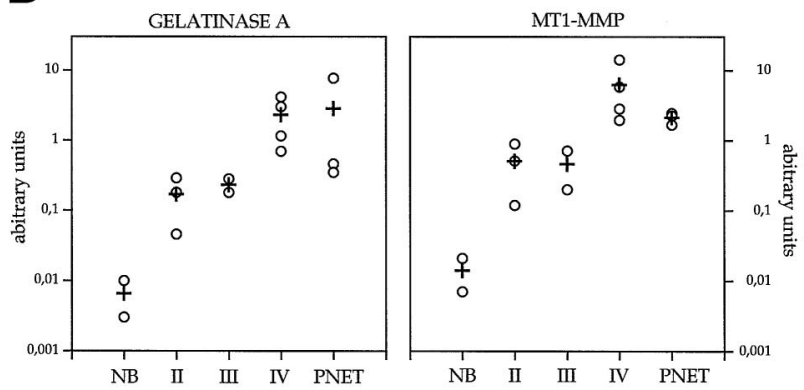

Figure 1. A:Northern blot analysis of MMP and TIMP mRNAs in normal brain (NB), low-grade astrocytoma (Astro II), anaplastic astrocytoma (Astro III), GBM, and medulloblastoma (PNET). In normal brain, we found high levels of TIMP-2, whereas TIMP-1 and all tested MMPs were expressed at low levels only. In low-grade astrocytomas and anaplastic astrocytoma, an increase in the expression of mt1-MMP, gelatinase A, and TIMP-1 was seen. The expression of these genes increased dramatically in GBM showing concomitant up-regulation of TIMP-1 mRNA. TIMP-2 was expressed in all tissues included in this study. In medulloblastomas, mt1-MMP and gelatinase A were overexpressed. mt2-MMP was up-regulated in two cases of medulloblastoma. B: Relative hybridization numbers $(\mathrm{O})$ and mean $(+)$ of mt1-MMP and gelatinase A mRNAs in normal brain (NB), low-grade astrocytoma (II), anaplastic astrocytoma (III), GBM (IV), and medulloblastoma (PNET). The mRNA levels were quantified by densitometric analysis using an Image Master System DTS (Pharmacia). GAPDH was used as loading control. The relative hybridization signal numbers were calculated by ascribing an arbitrary value of 1 to the least intense signal

mt1-MMP and gelatinase A were up-regulated in lowgrade and anaplastic astrocytoma. The expression of these genes was dramatically increased in GBM with concomitant up-regulation of TIMP-1 mRNA. TIMP-2 showed increased basal levels in all studied tissues. The 3.5- and 2.3-kb TIMP-2 transcripts were the most abundant. The mean expression of $\mathrm{mt1}-\mathrm{MMP}$ and gelatinase $\mathrm{A}$ in the different tumors is shown in Figure 1B. The levels of

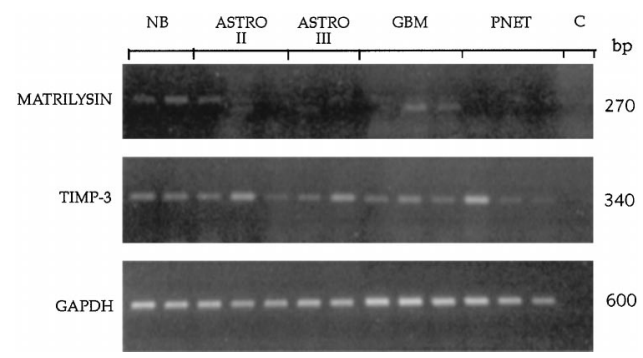

Figure 2. PCR analysis of matrilysin and TIMP-3 expression in human brain tumors. Signals appearing in the three lanes of the normal brain were about $350 \mathrm{bp}$ and therefore longer than the expected size of $270 \mathrm{bp}$. Some weak matrilysin expression was seen in two GBMs. TIMP-3 expression was seen in all tissues. NB, normal brain; Astro II, low-grade astrocytoma; Astro III, anaplastic astrocytoma; PNET, medulloblastoma; C, negative control.

gelatinase B were increased in three of four GBM. In medulloblastomas mt1-MMP and gelatinase A were overexpressed, but to a far lesser extent than observed in GBM. Moreover, in two of three medulloblastoma samples, mt2-MMP was dramatically up-regulated as compared with other tumors examined. In the third sample (a desmoplastic variant), an up-regulation of gelatinase $A$ was detected. Only a weak expression of mt3-MMP and of mt4-MMP (data not shown) was found in all tissues examined. Interestingly, in none of the tumors tested in this study did we observe detectable levels by Northern blot analysis of collagenases, stromelysins, matrilysin, metalloelastase, and RASI (data not shown).

\section{PCR Analysis Demonstrated Very Low Levels of Expression of Further MMP Genes}

Using PCR analysis, we did not find any detectable level of mRNA for collagenase 2, collagenase 3, and stromelysin 2 (data not shown). Very weak expression of collagenase, metalloelastase, stromelysins 1 and 3 , and RASI was observed in different probes without any correlation to the tumor grading or histology (data not shown). Weak matrilysin expression was seen in two GBM (Figure 2); TIMP-3 expression was seen in all tissues tested without any significant correlation to tumor grading (Figure 2). Results of PCR analysis are summarized in Table 1.

\section{Demonstration of Activated Forms of Gelatinases in Malignant Human Brain Tumors by Substrate Gel Electrophoresis}

We analyzed the secretion of gelatinases by substrate gel electrophoresis (zymography). With this method one can distinguish between the latent progelatinases and the activated enzyme forms. The respective progelatinases with a molecular weight of $92 \mathrm{kd}$ for progelatinase $\mathrm{B}$ and $72 \mathrm{kd}$ for progelatinase A are indicated in Figure 3. Below the latent forms appear the proteolytically activated species as a prominent complex of two or three bands. The zymography demonstrated a constitutive secretion of the latent forms of gelatinases A and B in every tumor examined, even in normal brain; however, in lowgrade astrocytomas and in normal brain, we did not find 


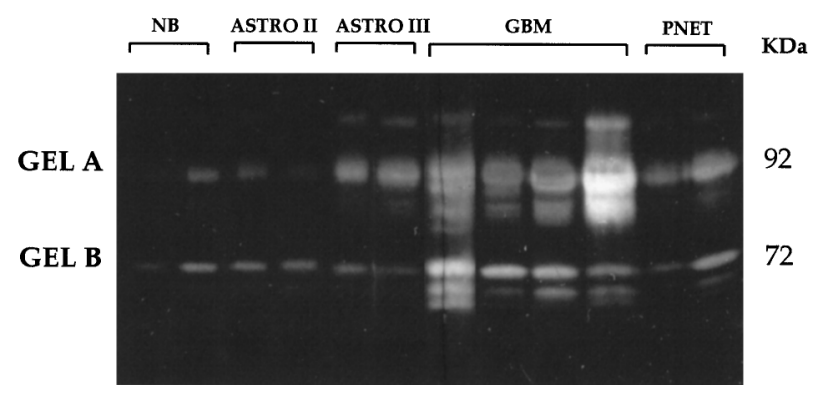

Figure 3. Gelatin substrate gel electrophoresis of normal brain, low-grade astrocytomas (Astro II), anaplastic astrocytoma (Astro III), GBM, and medulloblastoma (PNET). Indicated by $M_{\mathrm{r}} 92 \mathrm{kd}$ and by $M_{\mathrm{r}} 72 \mathrm{kd}$ are the progelatinase $\mathrm{B}$ and the progelatinase $\mathrm{A}$, respectively. Constitutive secretion of the latent forms of gelatinases A and B appeared in every tissue examined, including normal brain. In normal brain, low-grade astrocytomas, and anaplastic astrocytoma, no detectable amounts of the activated enzymes were found. In contrast, in GBM, an increase of active forms of gelatinases was clearly demonstrable, as indicated by a second and even a third band. In medulloblastomas, the level of proenzyme forms was high, with only barely detectable active forms of both gelatinases.

detectable amounts of the activated enzymes. In contrast, in GBM, an increase amount of active forms of gelatinases was clearly demonstrable as indicated by a second and even a third band (Figure 3). In medulloblastomas, the level of proenzyme forms was high, with only barely detectable active forms of both gelatinases. The results of zymography are summarized in Table 1.

\section{Immunostaining for mt1-MMP, Gelatinase A, Gelatinase B, and TIMP-2 in Human Brain Tumors and in Normal Brain}

Based on the results of Northern blots, we performed immunostaining of gliomas and medulloblastomas with anti-mt1-MMP, anti-gelatinase B, anti-gelatinase $\mathrm{A}$, and anti-TIMP-2. The findings of the immunostaining corroborate those of the Northern blot analysis. Positive staining for mt1-MMP was restricted to tumor cells; it was localized in the cell membrane and displayed a heterogeneous pattern with focal increase of immunoreactivity. Similarly, gelatinase A was identified in tumor cells, however, intracytoplasmatically and in partial co-localization with mt1-MMP. In low-grade astrocytomas, few cells displayed a sporadic, positive staining for gelatinase $A$ and mt1-MMP, whereas malignant gliomas and medulloblastomas showed an intense immunoreaction (Figure 4). One case of medulloblastoma was a desmoplastic variant and exhibited a distinct feature: the high cellular trabeculae of tumor cells, which were marked by reticulin deposition, showed an intense immunostaining for gelatinase $A$, whereas the reticulin-free islands stained predominantly for mt1-MMP (Figure 7).

Positive staining for gelatinase $\mathrm{B}$ was localized inside the cytoplasm of tumor cells; it was weak in medulloblastomas and low-grade astrocytomas, whereas glioblastomas were strongly stained. Immunostaining for TIMP-2 showed nests of positive cells in all tumors. Endothelial cells were immunostained with anti-gelatinase $B$ and TIMP-2. In normal brain, we found no specific immunoreactivity for mt1-MMP, gelatinase $A$, and gelatinase $B$.
TIMP-2 was detected in normal brain primarily in endothelial cells and in few astrocytes and neurons (Figure 5). Immunofluorescence with anti-mt1-MMP antibody and confocal laser microscopy clearly showed immunostaining on the cell membrane of tumor cells (Figure 6).

\section{Discussion}

Gliomas and medulloblastomas are neuroectodermal tumors with highly invasive potential. Degradation of extracellular matrix is a prerequisite for the invasive phenotype. $^{7}$ Significant evidence has accumulated to directly implicate members of the MMP gene family in this process. ${ }^{30}$ Given its important participation in matrix degradation, MMP regulation is complex and occurs predominantly at the level of gene expression. A second level of regulation occurs through the activation of the secreted proenzymes. ${ }^{13}$ Thus, to test the role of MMP family members in the invasion process, it is necessary to study not only their expression, but also whether the enzymes are present in their active form. In our study, we found upregulation of mt1-MMP mRNA levels in GBM with accompanying high expression of gelatinase $A$. This pattern was also observed in medulloblastomas, although the mRNA levels of the two enzymes were not as dramatically increased as observed in GBM. mt1-MMP was immunolocalized at the cell surface, whereas gelatinase A was found in the cytoplasm of tumor cells. Up-regulation of gelatinase B expression was found in three GBM and was related to the overexpression of gelatinase A. Using gelatin zymography, activated gelatinase $A$ and gelatinase $B$ were detected in all GBM.

Gelatinase A and B differ from other MMPs by their ability to interact, as latent proenzymes, with endogenous TIMP-2 and TIMP-1, respectively. ${ }^{31}$ The complex of TIMP-2 with the progelatinase A seemed to be essential for activation of progelatinase $A$, because this enzyme in the presence of TIMP-2 binds to and can be activated by a membrane-bound MMP (mt1-MMP) on the cell surface. ${ }^{28,32-34}$ It has been shown that activated gelatinase A itself is able to activate the progelatinase B. ${ }^{35}$ Also, stromelysin-1 and plasmin can activate gelatinase $B .^{36}$ However, in some tumors cells, these enzymes are not always co-expressed. In contrast, co-expression of gelatinase $A$ and $B$ was detected in different tumor tissues. ${ }^{35,37}$ The activation of progelatinase $B$ by gelatinase A may be significant in tissues in which stromelysin-1 may not be present. Thus, it is highly plausible that the following proteolytic cascade may enhance extracellular matrix degradation in malignant gliomas: increased expression of mt-MMP leading to activation of gelatinase A, which is able to activate gelatinase B. Our results support this hypothesis and are consistent with a recent report on increased expression of mt1-MMP and gelatinase $A$ in malignant gliomas: the increased expression of mt-MMP is correlated with the expression and activation of gelatinase $A$ and with histological progression of human gliomas in vivo. ${ }^{16}$

In Northern blot analysis, we could not detect mRNA of collagenases, stromelysins, matrilysin, metalloelastase, 


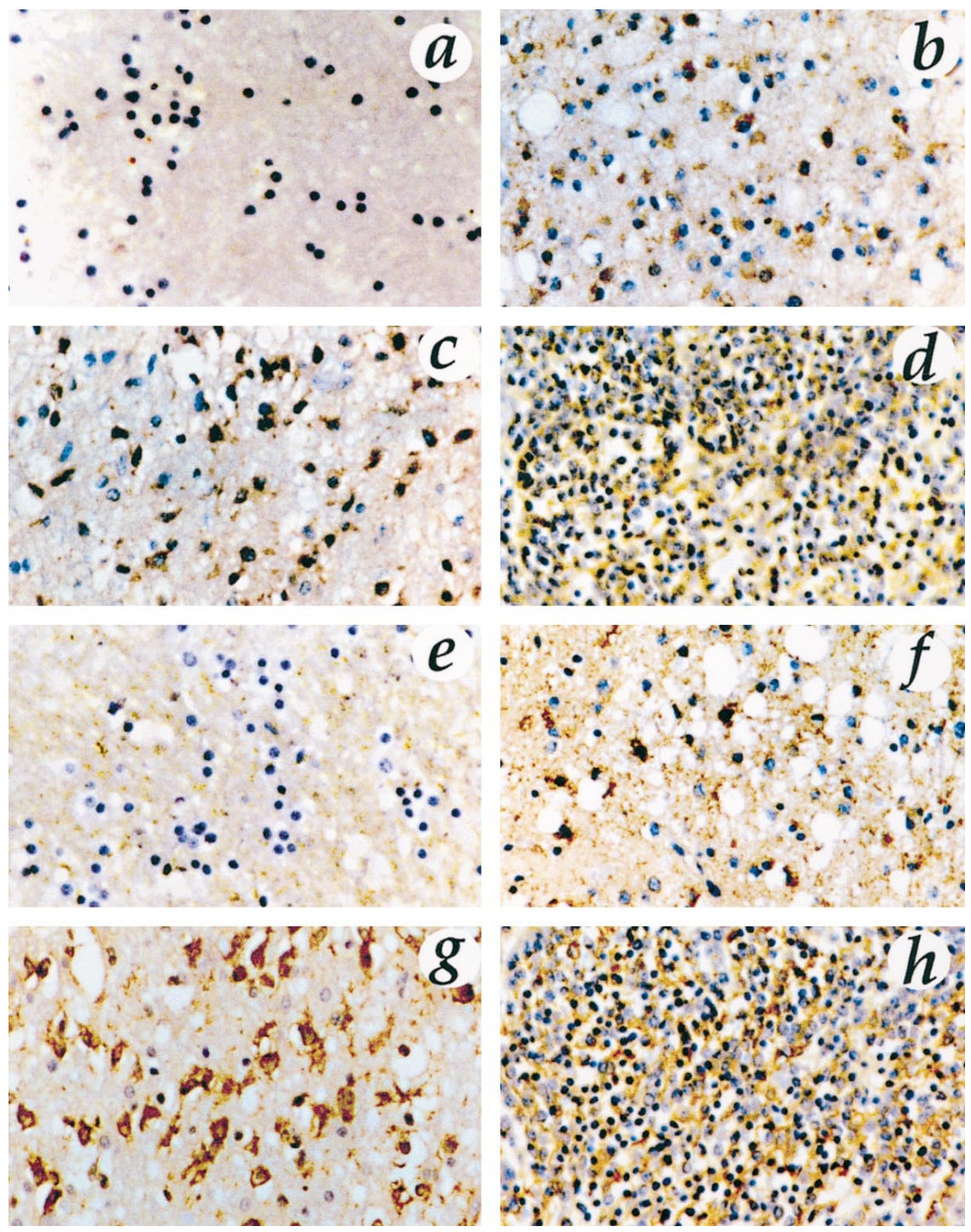

Figure 4. Immunostaining for gelatinase A (a to d) and mt1-MMP (e to $\mathrm{h}$ ) in normal brain (a and e), low-grade astrocytoma (b and f), GBM (c and g), and medulloblastoma $(\mathrm{d}$ and $\mathrm{h}$ ). Original magnification, $\times 313$. Normal brain showed no immunoreactivity. Staining was positive for mt1-MMP in tumor cells localized in the cell membrane. Gelatinase A was identified intracytoplasmatically in tumor cells and in partial colocalization with mt1-MMP. In low-grade astrocytomas, few cells displayed a sporadic, positive staining for gelatinase A and mt1-MMP, whereas malignant gliomas and medulloblastomas showed an intense immunoreaction.

and RASI in human brain tissues. Using PCR analysis, we found very low expression of stromelysin 3 . This enzyme is mainly associated with human breast cancer stroma cells, although its substrate specificity has not yet been defined. ${ }^{38}$ We also detected very low levels of matrilysin mRNA, which is found overexpressed in human breast and colonic carcinomas. ${ }^{38,39}$ Stromelysin 2 and interstitial collagenase have been detected in epidermoid carcinomas of the head and neck ${ }^{40}$ but were expressed only at very low basal levels in the tumors included in this report. These studies suggest that there may be organ- or cell type-specific expression of certain members of the MMP gene family in malignant tumors. From our present results, it can be speculated that the mt1-MMP/gelatinase A system may play a much more important role in malignant gliomas than other MMP. Corroborating this hypothesis, Deryugina et $\mathrm{al}^{41}$ have recently shown that transfection of glioma cells with cDNA encoding mt1-MMP resulted in increased cell surface activation of mt1-MMP and TIMP-2, constitutive activation of gelatinase A proenzyme, increased collagen degradation, and cell migration in tumor spheroid outgrowth assay.

Several studies have emphasized that the balance between MMP and their inhibitors is critical for control of proteolysis. ${ }^{40}$ In the literature, conflicting results are found regarding the expression of TIMP in gliomas. Mohanam et $\mathrm{al}^{15}$ reported that TIMP-1 and TIMP-2 were expressed in normal brain and in tumor tissues but were significantly lower in highly invasive glioblastomas. Lowgrade central nervous system tumors may thus produce proportionately more TIMP than high-grade tumors, which would then explain the different degrees of invasiveness. However, corroborating the results of Nakano et $\mathrm{al}^{19}{ }^{19}$ we found that TIMP-1 overexpression is closely related to the degree of malignancy in a given glioblastoma and to the overexpression of $\mathrm{mt1}-\mathrm{MMP} /$ gelatinase 


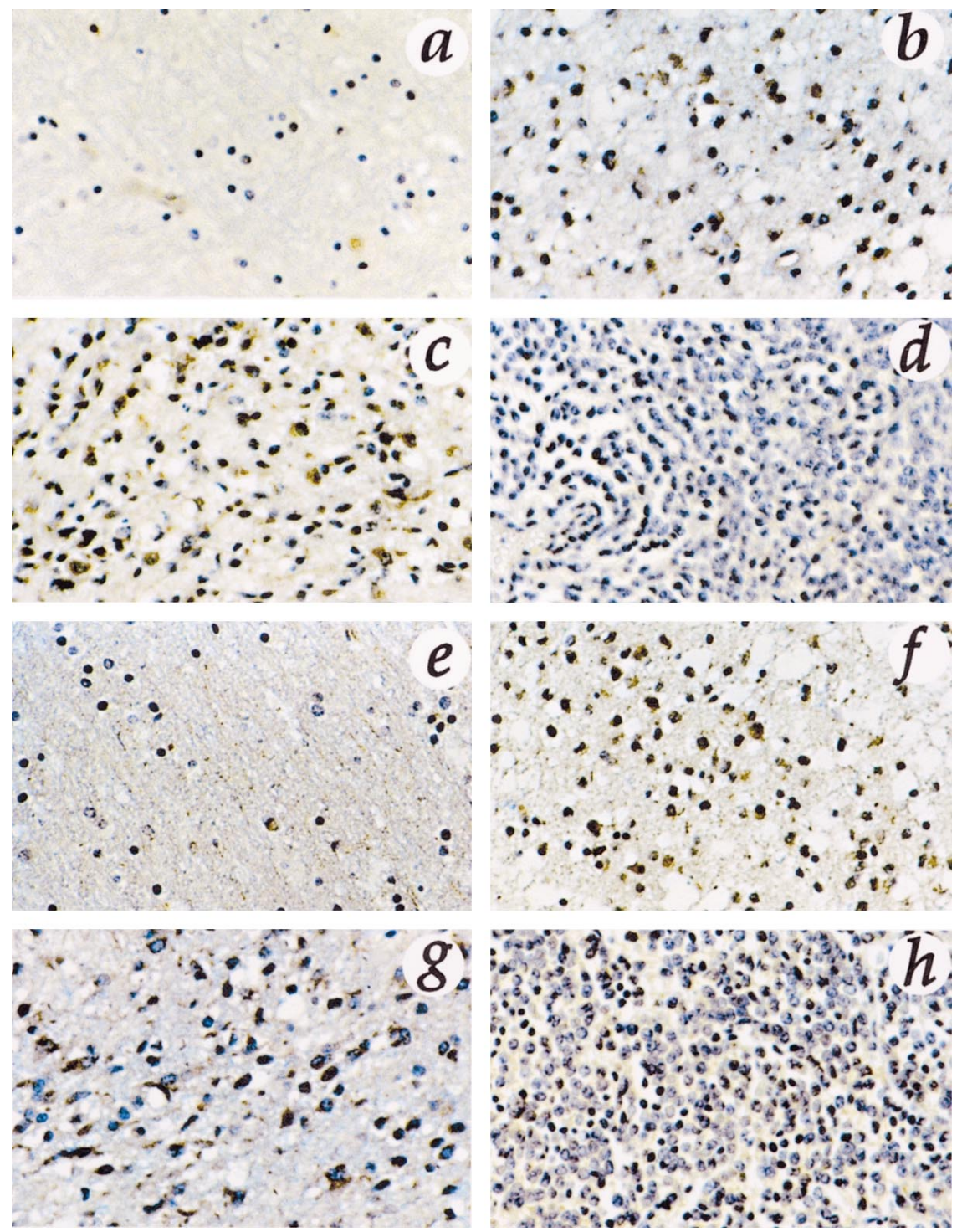

Figure 5. Immunostaining for gelatinase B (a to d) and TIMP-2 (e to $h$ ) in normal brain (a and e), low-grade astrocytoma (b and f), GBM (c and g), and medulloblastoma $(\mathrm{d}$ and $\mathrm{h})$. Original magnification, $\times 313$. Positive staining for gelatinase B was localized inside the cytoplasm of tumor cells; it was weak in medulloblastomas and low-grade astrocytomas, whereas glioblastomas were strongly stained. Immunostaining for TIMP-2 showed nests of positive cells in all tumors. Endothelial cells were immunostained with anti-gelatinase B and TIMP-2. TIMP-2 was detected in normal brain primarily in endothelial cells and in few astrocytes and neurons.

A. It is thus tempting to speculate that the overexpression of TIMP-1 may prevent the excess action of MMP.

We detected TIMP-2-increased levels in all tissues examined. In neoplastic brain tissue, TIMP-2 was detectable by immunohistochemistry in a high percentage of tumor cells. In normal brain, TIMP-2 localized to endothelial cells and sporadically occurred in astrocytes and neurons. The constitutive expression of TIMP-2 in normal brain is still poorly understood.

Recently, a third member of the TIMP family has been described: TIMP-3 inhibits, as do TIMP-1 and TIMP-2, collagenase-1, stromelysin-1, and gelatinase $\mathrm{A}$ and B. ${ }^{42,43}$ In gliomas, medulloblastomas, and normal brain, we found very low expression of TIMP-3. This finding suggests that TIMP-3 is probably not involved in the regulation of MMP in brain tumors.

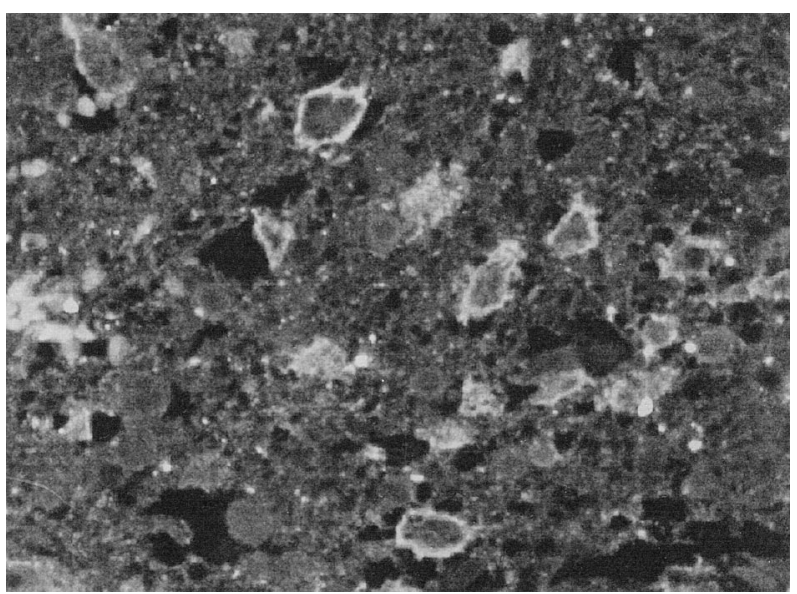

Figure 6. Immunofluorescence with anti-mt1-MMP antibody and confocal laser microscopy clearly showed immunostaining on the cell membrane of tumor cells. Original magnification, $\times 400$. 

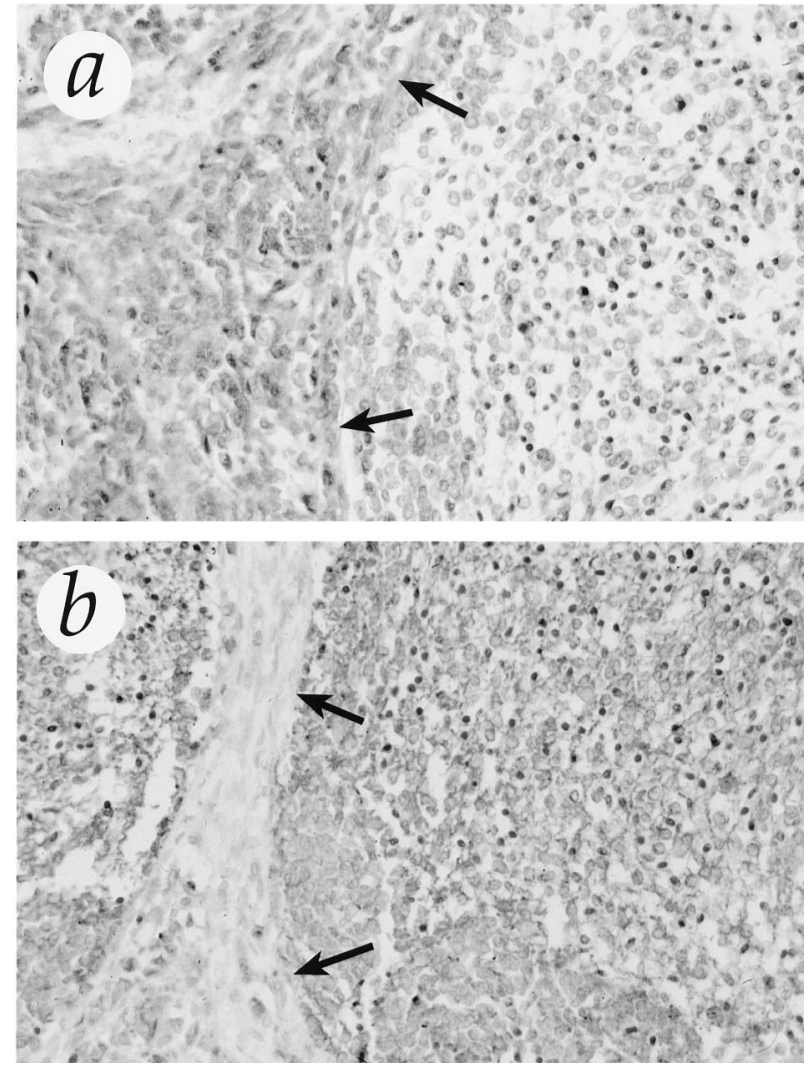

Figure 7. Immunostaining for gelatinase A (a) and mt1-MMP (b) in desmoplastic medulloblastoma. The high cellular trabeculae of tumor cells (arrows) showed an intense immunostaining for gelatinase A, whereas the reticulinfree islands stained predominantly for mt1-MMP. Original magnification, $\times 313$.

One characteristic of medulloblastomas is their tendency of leptomeningeal invasion and subsequent spread within the cerebrospinal fluid. ${ }^{44}$ Although this property is of considerable clinical relevance, the underlying mechanism is poorly understood. The present study demonstrates for the first time that medulloblastomas express high levels of MMP. An interesting aspect was observed in a desmoplastic medulloblastoma: the high cellular trabecula showed intense immunostaining for gelatinase $\mathrm{A}$, whereas the islands of more differentiated cells exhibited strong reactivity for mt1-MMP. This particular localization pattern is intriguing and suggests that different populations of cells may interact to activate the cascade of gelatinase A. The two other medulloblastomas included were the only tumors that exhibited a high expression of mt2-MMP. This membrane-bound enzyme has been shown to activate like mt1-MMP, the progelatinase $A$, and progelatinase A-TIMP-2 complexes. ${ }^{45} \mathrm{Al}-$ though the small number of cases does not allow us to draw a definitive conclusion, these preliminary results suggest that MMP may play an important role in determining the biological behavior of medulloblastomas. Additional studies on the expression of MMP in medulloblastoma are certainly warranted.

In conclusion, the results of this study indicate that the mt1-MMP/gelatinase A system may play a critical role in the mechanism of local tumor invasion observed in malignant gliomas. The overexpression of MMP is accom- panied by a concomitant up-regulation of TIMP-1. Future attempts to specifically block MMP enzyme activity or increase TIMP-1 local expression may provide a novel means to inhibit brain tumor invasiveness.

\section{Acknowledgments}

We thank Dr. Axel Pagenstecher and Dr. Karl Plate for many insightful discussions and critical review of the manuscript. We gratefully acknowledge Irene Lethenet for technical assistance.

\section{References}

1. Giles, GG, Gonzales MF: Epidemiology of brain tumors and factors in prognosis. Brain Tumors, ch 4. Edited by AH Kaye, ER Laws. New York, Churchill Livingstone, 1995, pp 47-67

2. Gold EB: Epidemiology of brain tumors. Reviews in Cancer Epidemiology, vol 1. Edited by AM Lilenfeld. North Holland, the Netherlands, Elsevier, 1980, pp 245-292

3. Cerame MA, Guthikonda M, Kohli, CM: Extraneural metastases in gliosarcomas: a case report and review of literature. Neurosurgery 1985, 17:413-418

4. Rutka JT, Dougherty DV, Giblin JR, Edwards MS, McCulloch JR, Rosenblum ML: Growth of a medulloblastoma on normal leptomeningeal cells in culture: interaction of tumor cells and normal cells. Neurosurgery 1987, 21:872-878

5. Berger MS, Magrassi L, Geyer R: Medulloblastomas and primitive neuroectodermal tumors. Brain Tumors, ch 30. Edited by AH Kaye, Laws ER. New York, Churchill Livingstone, 1995, pp 562-574.

6. Liotta LA, Tryggvason K, Garbisa S, Hart I, Foltz CM, Shafie S: Metastatic potential correlates with enzymatic degradation of basement membrane collagen. Nature 1980, 284:67-68

7. Matrisian LM: The matrix-degrading metalloproteinases. Bioessays 1992, 14:455-463

8. Birkedal-Hansen H, Moore WG, Bodden MK, Windsor LJ, BirkedalHansen B, DeCarlo A, Engler JA: Matrix metalloproteinases: a review. Crit Rev Oral Biol Med 1993, 4:197-250

9. Stetler-Stevenson WG, Aznavoorian S, Liotta LA: Tumor cell interactions with extracellular matrix during invasion and metastasis. Annu Rev Cell Biol 1993, 9:541-573

10. Behredtsen O, Werb Z: Metalloproteinases regulate parietal endoderm differentiating and migrating in cultured mouse embryos. Dev Dyn 1997, 208:255-265

11. Nagase H, Okada Y: Proteinases and matrix degradation. Textbook of Rheumatology. Edited by WN Kelley, ED Harris, S Ruddy, CB Sledge. Philadelphia, WB Saunders Company, 1996, pp 332-341

12. Woessner JF: The family of matrix metalloproteinases. Ann NY Acad Sci 1994, 732:11-21

13. Woessner JF: Matrix metalloproteases and their inhibitors in connective tissue remodeling. FASEB J 1991, 5:2145-2154

14. Greene J, Wang M, Liu YI, Raymond LA, Rosen C, Shi YI: Molecular cloning and characterization of human tissue inhibitor of metalloproteinase 4. J. Biol. Chem 1996, 271:30375-30380

15. Mohanam S, Wang WW, Rayford A, Yamamoto M, Sawaya R, Nakajima M, Liotta LA, Nicolson GL, Stetler-Stevenson WG, Rao JS: Expression of tissue inhibitors of metalloproteinases: negative regulators of human glioblastoma invasion in vivo. Clin Exp Metastasis 1995, 13:57-62

16. Yamamoto M, Mohanam S, Sawaya R, Fuller GN, Seiki M, Sato $H$, Gokaslan ZL, Liotta LA, Nicolson GL, Rao JS: Differential expression of membrane-type matrix metalloprotease and its correlation with gelatinase A activation in human malignant brain tumors in vivo and in vitro. Cancer Res 1996, 56:384-392

17. Apodaca G, Rutka JT, Bouhana K, Berens ME, Giblin JR, Rosenblum $\mathrm{ML}$, Mckerrow JH, Banda MJ: Expression of metalloproteinases and metalloproteinase inhibitors by fetal astrocytes and glioma cells. Cancer Res 1990, 50:2322-2329

18. Nakano A, Tani E, Miyazaki K, Furuyama J, Matsumoto T: Expression 
of matrilysin and stromelysin in human glioma cells. Biochem Biophys Res Commun 1993, 192:999-1003

19. Nakano A, Tani E, Miyazaki K, Yamamoto Y, Furuyama J: Matrix metalloproteinases and tissue inhibitors of metalloproteases in human gliomas. J Neurosurg 1995, 83:208-307

20. Kleihues P, Burger PC, Scheithauer BW: Histological Typing of Tumors of the Central Nervous System, Ed 2. Berlin, Springer Verlag, 1993

21. Chomczynsky P, Sacchi N: Single-step method of RNA isolation by acid guanidinium thiocyanate-phenol-chloroform extraction. Anal Biochem 1987, 162:156-159

22. Conca W, Willmroth F: Human T lymphocytes express a member of the Matrix Metalloproteinase gene family. Arthritis Rheum 1994, 37: 951-956

23. Huhtala P, Eddy RL, Fan YS, Byers MG, Shows TB, Tryggvason K: Completion of the primary structure of the human type IV collagenase preproenzyme and assignment of the gene (CLG4) to the q21 region of chromosome 16. Genomics 1990, 6:554-559

24. Wilhelm SM, Collier IE, Marmer BL, Eisen AZ, Grant GA, Goldberg GI: SV40-transformed human lung fibroblasts secrete a 92-kd type IV collagenase which is identical to that secreted by normal human macrophages [published erratum appears in J Biol Chem 1990 25; 265:22570]. J Biol Chem 1989, 264:17213-17221

25. Anglard P, Melot T, Guerin E, Thomas G, Basset P: Structure and promoter characterization of the human stromelysin-3 gene. J Biol Chem 1995, 270:20337-20344

26. Muller D, Quantin B, Gesnel MC, Millon-Collard R, Abecassis J, Breathnach R: The collagenase gene family in humans consists of at least four members. Biochem J 1988, 253:187-192

27. Kolb C, Mauch S, Peter HH, Krawinkel U, Sedlacek R: The matrix metalloproteinase RASI- 1 is expressed in synovial blood vessels of a rheumatoid arthritis patient. Immunol Lett 1997, 57:83-88

28. Okada A, Bellocq JP, Rouyer N, Chenard MP, Rio MC, Chambon P, Basset P: Membrane-type matrix metalloproteinase (MT-MMP) gene is expressed in stromal cells of human colon, breast, and head and neck carcinomas. Proc Natl Acad Sci USA 1995, 92:2730-2734

29. Puente XS, Pendas AM, Llano E, Velasco G, Lopez-Otín C: Molecular cloning of a novel membrane-type matrix-metalloproteinase from a human breast carcinoma. Cancer Res 1996, 56:944-949

30. Rao JS, Steck PA, Mohanam S, Stetler-Stevenson WG, Liotta LA, Sawaya R: Elevated levels of $M_{r}$ 92,000 type IV collagenase in human brain tumors. Cancer Res 1993, 53:2208-2211

31. Stetler-Stevenson WG, Krutzch HC, Liotta LA: Tissue inhibition of metalloprotease (TIMP-2): a new member of the metalloprotease inhibitor family. J Biol Chem 1989, 264:17374-17378
32. Sato H, Takino T, Yasunori O, Cao J, Shinagawa EY, Seiki M: A matrix metalloproteinase expressed on the surface of invasive tumor cells. Nature 1994, 370:61-65

33. Takino $T$, Sato $H$, Shinagawa A, Seiki M: Identification of the second membrane-type matrix-metalloproteinase (MT-MMP-2) gene from a human placenta cDNA library. J Biol Chem 1995, 270:23013-23020

34. Will $H$, Hinzmann B: cDNA sequence and mRNA tissue distribution of a novel human matrix metalloproteinase with a potential transmembrane segment. Eur J Biochem 1995, 231:602-608

35. Fridman R, Toth M, Peña D, Mobashery S: Activation of progelatinase B (MMP-9) by gelatinase A (MMP-2). Cancer Res 1995, 55:25482555

36. Ogata Y, Enghild JJ, Nagase H: Matrix metalloprotease 3 (stromely$\mathrm{sin}$ ) activates the precursor for the human matrix metalloprotease 9. J Biol Chem 1992, 267:3581-3584

37. Polette M, Clavel C, Cockett M, Bentzmann SG, Murphy G, Birembaut $P$ : Detection and localization of mRNAs encoding matrix metalloproteases and tissue inhibitors in human breast pathology. Invasion Metastasis 1993, 13:31-37

38. Basset P, Bellocq JP, Wolf C, Stoll I, Hutin P, Limacher JM, Podhajcer OL, Chenard MP, Rio MC, Chambon P: A novel metalloprotease gene specifically expressed in stroma cells of breast carcinomas. Nature 1990, 348:699-704

39. Yamamoto $\mathrm{H}$, Itoh F, Hinoda $\mathrm{Y}$, Senota A, Yoshimoto M, Nakamura $\mathrm{H}$, Imai K, Yachi A: Expression of matrilysin mRNA in colorectal adenomas and its induction by truncated fibronectin. Biochem Biophys Res Commun 1994, 201:657-664

40. Kohn E, Liotta LA: Molecular insights into cancer invasion: strategies for prevention and intervention. Cancer Res 1995, 55:1856-1862

41. Deryugina El, Bourdon MA, Luo G-X, Reisfeld RA, Strogin A: Matrix metalloprotease-2 activation modulates glioma cell migration. J Cell Science 1997, 110:2473-2482

42. Uría JA, Ferrando AA, Velasco G, Freije JMP, Lopez-Otín C: Structure and expression in breast tumors of human TIMP-3, a new member of metalloprotease inhibitor family. Cancer Res 1994, 54:2091-2094

43. Apte SS, Mattei MG, Olsen BR: Cloning of the cDNA encoding human tissue inhibitor of metalloproteinase-3 (TIMP-3) and mapping of the TIMP3 gene to chromosome 22. Genomics 1994, 19:86-90

44. Deutsch M, Reigel DH: The value of myelography in the management of childhood medulloblastoma. Cancer 1980, 45:2194-2197

45. Kolkenbrock H, Hecker-Kia A, Orgel D, Ulbrich N, Will H: Activation of progelatinase $A$ and progelatinase A/TIMP-2 complex by membrane type-2-matrix metalloprotease. J Biol Chem 1997, 378:71-76 